\title{
Analysis for the Implementation of LPV Approaches in the Czech Republic
}

\author{
Tomas Droppa \\ Department of Air Transport \\ Department of Air Transport, Faculty of Transportation \\ Sciences, Czech Technical University \\ Horská 3, Praha 2, 128 03, Czech Republic
}

\author{
Jakub Kraus \\ ATM Systems Laboratory, \\ Department of Air Transport, Faculty of Transportation \\ Sciences, Czech Technical University \\ Horská 3, Praha 2, 128 03, Czech Republic \\ e-mail: kraus@fd.cvut.cz
}

\begin{abstract}
This paper deals with the implementation of LPV approaches in the Czech Republic. The main aim of the research is to create a detailed analysis, specifying the appropriate parameters in line with the selected implementation options of the LPV approach, as component of IFR and with the possibility of using them as advisory system based on LPV approach for VFR segment of general aviation.
\end{abstract}

Keywords- LPV approach, cloud break procedures, general aviation, IFR

\section{INTRODUCTION}

The localizer performance with vertical guidance (LPV) approach is a procedure that is fully utilized for its many benefits throughout the U.S. and Canada. Since 2011 LPV is gradually being implemented in Europe. It is for this reason that there is a need to create implementation procedures for the Czech Republic. The main objective of this paper is to produce a comprehensive view of the LPV approach, specifying whether the implementation is appropriate, at which aerodromes, in what form and under what conditions. The basis for this paper are professional foreign journal articles, AIP and the questionnaire results from a group of Czech pilots.

\section{APPROACH TO LANDING}

Today's aviation legislation within the Czech Republic recognizes three basic types of approach; the precision approach (PA), the non-precision approach (NPA) and the approach with vertical guidance (APV). Within the area of precision approaches, we include the most widely used systems such as; ILS, GBAS, MLS but also the PAR system. These are systems that provide both vertical and horizontal guidance for aircraft through the phase of approach and throughout the continuous descent. The second category, non-precision approaches, will include approaches utilizing ground navigation equipment such as NDB, VOR, DME as well as the global navigation satellite system known as GNSS along the lateral line. The third type is the approach with vertical guidance, which is defined as any approach with vertical guidance, which is not a precision approach.

- Precision Approach (PA): is the most accurate approach method. The first type is the ILS approach, which provides horizontal guidance LLZ and vertical guidance GP. This approach has three categories defined according to specified minimums. The minimums of Cat I. approximates to the LPV approach. Another similar type of approach uses a microwave system called MLS, based on providing horizontal and vertical guidance. An alternative type of approach is the GLS, where GPS provides horizontal guidance and vertical guidance is provided by the GBAS system, this category also includes PAR - mostly used by the military.

- Non-precision approach (NPA): this includes all the classic approach techniques using conventional navigation devices such as NDB, DME, VOR, and LLZ. This type of approach provides only horizontal guidance. NPA also consists of the RNAV (GNSS) approach. It uses one of the systems GPS, GLONASS or Galileo (in the near future) and is provided only along the horizontal line. According to ICAO Doc. 9613, this type of approach is known as the lateral navigation (LNAV) approach.

- Approaches with vertical guidance APV: Include two types of approach; the less precise is APV Baro, where the horizontal line is secured by GPS and vertical guidance is provided by a system of certified barometric height sensors. Within the ICAO Doc. 9613 we find the indicated LNAV / VNAV published minima. A more precise type of approach in this category is the APV SBAS approach, where the vertical and horizontal guidance is provided by one of the main GNSS systems and SBAS. The ICAO Doc. 9613 is the point of reference for this type of approach as LPV approach is the most accurate approach using SBAS. 


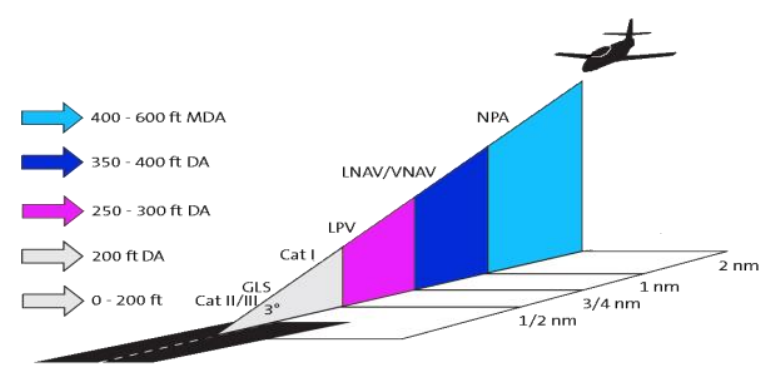

Figure 1. Approach comparison

The basic rules specifying the required accuracy, availability, continuity and integrity of approach systems are available within the above mentioned ICAO Doc. 9613 called Performance-based Navigation Manual. This document specifies requirements for the performance of installations in phase of approach (RNP) and distributes them as follows:

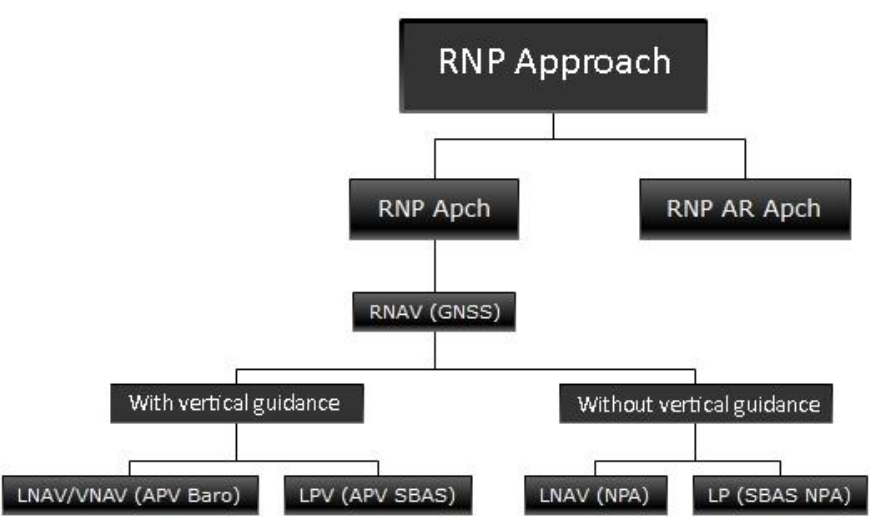

Figure 2. PBN classification

General Aviation (GA) is a part of aviation, which is, due to the characteristics of evolution within the industry, always behind commercial and military aviation, despite this fact it represents the largest group. In spite of this there have been no significant evolutionary changes within general aviation for decades.

With the increasing number of general aviation aircraft there is a need for innovation, improved procedures, increased safety and improved air traffic flow efficiency. Based on ICAO recommendations the implementation of applications using SBAS is of increasing importance.

General aviation can be divided into two main areas, Visual Flight Rules (VFR) and Instrument Flight Rules (IFR). While the LPV approach as an IFR component of general aviation creates a new, very profitable approach, for VFR aircraft it is more about supporting applications, increased safety and also the availability of VFR flying.

\section{IMPLEMENTATION OF LPV APPROACH FOR IFR}

The first option is the implementation of the LPV for IFR airports, which already have the necessary infrastructure and meet the requirements of national regulation, in this case L14 for precision runways. Implementation of the LPV approach is very easy at airports with an IFR runway already established within its infrastructure. The primary advantages of implementation are cost-effectiveness and availability. When we compare this system with ILS, its price is significantly lower, with implementation and operating costs being minimal for the operator. The other advantage is the applicability of the system for either runway direction.

The most important airport group for the implementation of the LPV approach is IFR airports which currently only have the NDB approach, but have the necessary infrastructure to support LPV. In this case LPV would mean a substantial reduction in the minima, improved level of safety and lower operational costs.

TABLE I. LIST OF IFR AIRPORTS IN CZECH REPUBLIC

\begin{tabular}{|l|c|c|c|}
\hline \multicolumn{1}{|c|}{ Airport } & $\begin{array}{c}\text { ICAO } \\
\text { code }\end{array}$ & $\begin{array}{c}\text { Published } \\
\text { Approach }\end{array}$ & $\begin{array}{c}\text { Published } \\
\text { GNSS } \\
\text { approach }\end{array}$ \\
\hline Brno / Tuřany & LKTB & $\begin{array}{c}\text { ILS, VOR, } \\
\text { NDB }\end{array}$ & $\begin{array}{c}\text { LNAV } \\
\text { LNAV/VNAV } \\
\text { LPV }\end{array}$ \\
\hline Karlovy Vary & LKKV & ILS, NDB & - \\
\hline Kbely & LKKB & ILS, NDB & - \\
\hline Kunovice & LKKU & NDB & - \\
\hline $\begin{array}{l}\text { Ostrava } \\
\text { Mošnov }\end{array}$ & LKMT & $\begin{array}{c}\text { ILS, VOR, } \\
\text { NDB }\end{array}$ & $\begin{array}{c}\text { LNAV/VNAV } \\
\text { LPV }\end{array}$ \\
\hline Pardubice & LKPD & ILS, NDB & - \\
\hline $\begin{array}{l}\text { Praha/ } \\
\text { V. Havla }\end{array}$ & LKPR & ILS, VOR, & $\begin{array}{c}\text { LNAV } \\
\text { NDB }\end{array}$ \\
\hline Vodochody & LKVO & ILS, NDB & LNAV \\
\hline
\end{tabular}

\section{IMPLEMENTATION OF LPV APPROACH FOR VFR}

There is also great potential for the development of general aviation with the implementation of LPV approach into aerodromes that currently do not have an instrument approach. It would increase the usability of airport infrastructure with IFR arrival procedures, which would increase the possibility of the landing in bad weather or other unexpected conditions. It would also increase the opportunities for general aviation pilots and flight schools. The implementation could reduce costs for flight schools, which could be reflected in the final price for flight school customers. In the Czech Republic there are 84 certified VFR aerodromes. Due to safety reasons this paper is focused on the longest runways of the aerodromes for aerodromes with more than one runway. 
TABLE 2: AERODROMES WiTH PAVED RWY

\begin{tabular}{|c|c|c|c|}
\hline Aerodrome & $\begin{array}{c}\text { ICAO } \\
\text { code }\end{array}$ & $\begin{array}{c}\text { RWY } \\
\text { Length }\end{array}$ & $\begin{array}{c}\text { Supplement } \\
\text { equipment }\end{array}$ \\
\hline České Budějovice & LKCS & 2500 & PAPI \\
\hline Hořovice & LKHV & 1170 & - \\
\hline Hosín & LKHS & 800 & - \\
\hline Hradec Králové & LKHK & 2400 & PAPI \\
\hline Jindřichův Hradec & LKJH & 700 & - \\
\hline Kř́ženec & LKKC & 595 & - \\
\hline Mnichovo Hradiště & LKMH & 1550 & - \\
\hline Moravská Třebová & LKMK & 714 & - \\
\hline Olomouc & LKOL & 420 & - \\
\hline Otrokovice & LKOT & 650 & - \\
\hline Panenský Týnec & LKPC & 2505 & - \\
\hline Plzeň & LKLN & 1450 & - \\
\hline Přerov & LKPO & 2500 & - \\
\hline Př́bram & LKPM & 1450 & - \\
\hline Vysoké Mýto & LKVM & 600 & APAPI info \\
\hline & & &
\end{tabular}

If we focuses on the fact of presence of Flight Schools, we would get a shorter list of aerodromes for the implementation of LPV:

\section{○ Benešov LKBE \\ ○ Letňany LKLT \\ ○ Př́ibram LKPM \\ - České Budějovice LKCS \\ ○ Hořovice LKHV \\ ○ Hradec Králové LKHK \\ ○ Olomouc LKOL}

The aerodromes Benešov LKBE and Letňany LKLT do not have paved runways, but due to the frequency of aircraft movements and the number of flight schools, they have been included in the final list.

\section{A. Advisory system for $C D O$}

In September 2008 the Plan for flight efficiency was signed in Geneva. It was partially an agreement to streamline the environmental, economic and safety sector. The plan therefore includes Continuous Descent Operations (CDO) for continuous descent to eliminate step-down fixes. This procedure guides the aircraft to the final approach point with the minimum use of engine thrust and relatively minimal drag. This has three results; the decrease of fuel consumption reduces the amount of emissions and leads to reductions in noise levels. Based on the survey done in Czech Republic in February 2014, there are many SBAS receivers already on board of the aircraft. $56 \%$ of the respondents already have an SBAS receiver on board their VFR aircraft, which could in the future help the introduction of CDO.

\section{B. Advisory system for VFR flying in time of sunset}

In order to increase the safety of VFR flying there is the possibility to use LPV as an advisory system for the purpose of landing at the final destination. Under all circumstances, the conditions must fall within VMC regulations; therefore, visibility, cloud ceiling, cloud coverage and distance from the clouds must be within required parameters. The system could give the ability to land within 15 minutes after the civil twilight time without the need to fulfil further flight plans or land at the alternate. To prevent abuse of this procedure; it should only be used for the completion of a navigation flight longer than 15 minutes and not by flights in the vicinity of the aerodrome, within a 10NM radius of the aerodrome reference point. The destination should be certified for VFR night and at the time of landing runway lights have to be fully operational, which ensures visual contrast of the runway and the surrounding land.

The main aim of this procedure is to increase the level of safety for pilots flying at the end of the day, allowing them to simplify the approach and landing. The motive is to maintain situational awareness, allowing time for preparation and full concentration for landing rather than fulfilling the flight plan during the flight. The MAP mode with synthetic vision based on database obstacle limitation is an additional function available on some aircraft that would further help in simplifying the approach.

\section{Cloud Break Procedure}

The cloud break procedure (CBP) would be used for breaking clouds during VFR flights with the intent to land at aerodromes under cloud cover. Throughout this procedure it would be necessary to update the national aviation regulations, in particular regulation L 2 Rules of the Air - Chapter 4, by adding except during the CBP.

In practice this would mean that the pilot can fly above the clouds coverage in excess of 4/8 only if they initiate the CBP. Before starting the procedure the pilot must be familiar with the cloud base, which should not be less than $1500 \mathrm{ft}$, to preserve the rules of visual flight. In addition, the pilot must report his position and the entry point for the start of the CBP. The entry point into the pattern would be the point from the GPS database which maintains grid height or MOCA. The height above the obstacle limitations must be ensured throughout the whole procedure. To maintain a continuous descent at a standard approach angle, it is necessary to construct two entry points lying in the same line with increasing distance from the expected downwind position. The entry point would be determined by the height of the flight. This would ensure that VFR pilots without an IFR certificate do not stay within the cloud cover too long and thus protect them against illusion.

It would be also useful to implement advanced exercises in the PPL training for this procedure. The basic block already exists in the PPL, syllabus called exercise for approaching based on LLZ.

The CBP should be designed and carried out in order to be finished shortly before the downwind position is reached. The airplane would then proceed to the aerodrome circuit from the downwind position at $1,000 \mathrm{ft}$ above the surface. Thus, 
allowing a spacing of at least 500ft from the clouds. This procedure would be completed by the announcement of the downwind position.

This procedure is designed as supporting element, only for the purpose of CBP with intent to land at an aerodrome below the cloud cover. Similarly there must be described the minimum descent altitude for each aerodrome. It is necessary to construct the route taking into account local topography and in accordance with local procedures, allowing the pilot to climb directly to the original altitude in case of missed approach. The pilot shall only initiate the procedure with the information of the estimated cloud base above the aerodrome, which will avoid the cancelation of the procedure. After climbing to the original height out of the clouds, the pilot should continue to alternate in visual meteorological conditions (VMC).
If it appears that there is another plane in the cloud brake procedure, when entering the RMZ zone, the procedure should be aborted, until the plane that is in CBP completes it. An aircraft that is waiting to enter CBP would enter the VFR holding pattern until the CBP is clear. The VFR pattern is similar to the holding pattern for the IFR approach. The only difference is that VFR holding pattern is not defined by flight time of flight in each leg or by fixes. The VFR pattern has recommended shape of aerodrome circuits. The priority and main requirement is to fly according to the VFR flight regulations when holding.

In order to avoid the unwanted conflict of VFR traffic there is established the required entry point to the RMZ zone where pilots are obliged to enter and report their position. Conflict between VFR traffic and aircraft from missed procedure is excluded by condition, that holding pattern is possible to fly only in VMC according regulations.

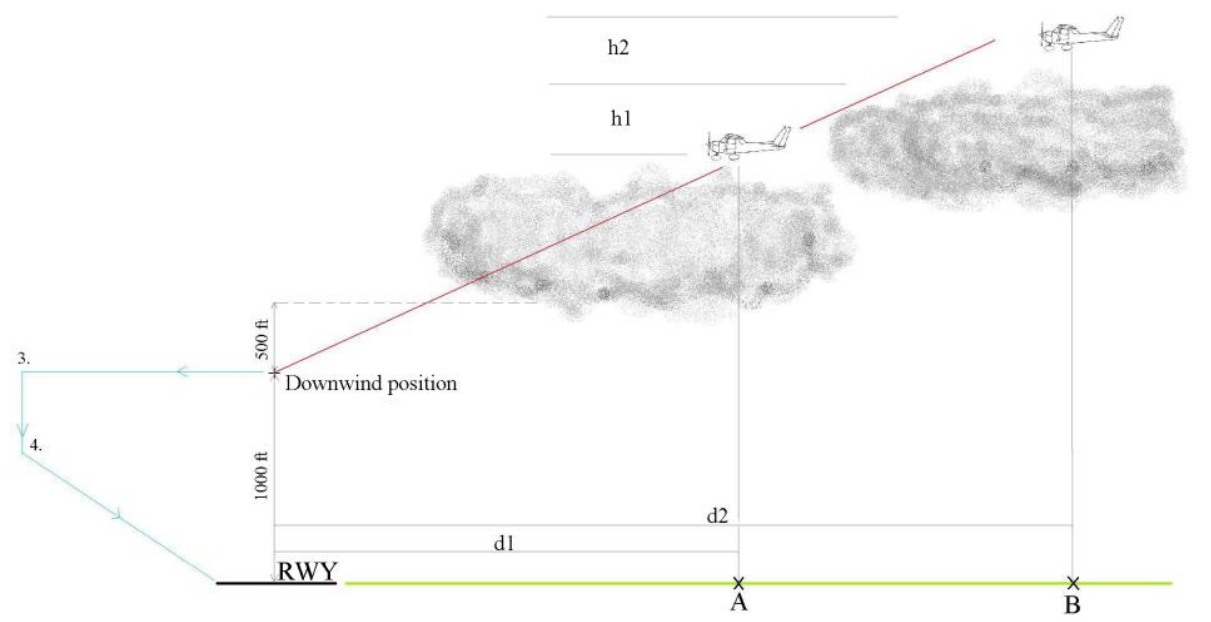

V. CONCLUSION

There is a need to improve General Aviation and this paper show that this can be achieved through the implementation of LPV techniques. The implementation of LPV should at first be focused at IFR capable airports. Based on advantages of the LPV approach procedure and implemented receivers in aircraft, it seems appropriate to publish advisory applications based on the LPV approach construction for VFR flying. There are three mentioned applications for VFR, $\mathrm{CBP}$, the advisory system for CDO and the advisory system for sunset flying. To protect separation between aircraft and

Figure 3: CBP construction basic safety minima, it is necessary to set up Airspace classification in the location, where the procedure is published. One of the solutions would be radio mandatory zones.

\section{REFERENCES}

[1] AIP ČR [online].Available at <http://lis.rlp.cz/ais_data/www_main_control/frm_cz_aip.htm>

[2] L standards - ICAO Annexes [online]. Available at <http://lis.rlp.cz/predpisy/predpisy/index.htm>

[3] Performance-based Navigation (PBN) Manual. Doc 9613 AN/937 [online]. Available at:

<http://www.caac.gov.cn/dev/fbs/xjsyy/201110/P020111010540008641 095.pdf>

[4] European Aviation Safety Agency. AMC 20-28. [online]. Available at: $<$ http://easa.europa.eu/system/files/ dfu/Annex\%20II\%20-\%20AMC\% 2020-28.pdf>

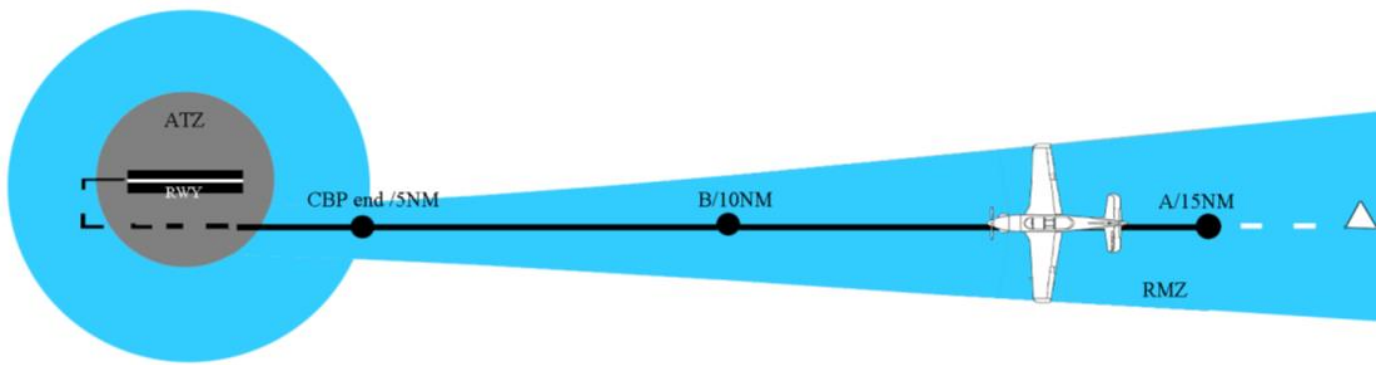

Figure 4: RMZ construction 